\title{
Synthesis of BMS-644950
}

Key words

BMS-644950

HMG-CoA reductase inhibitors

\section{statins}

Biginelli reaction

pyrimidines

Julia-Kocienski olefination

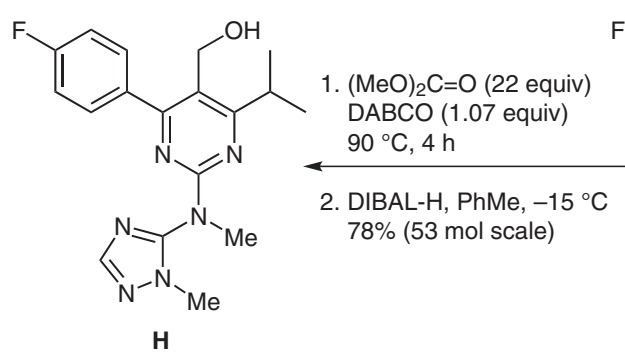<smiles>COC(=O)c1c(-c2ccc(F)cc2)nc(Nc2ncnn2C)nc1C(C)C</smiles>

\section{$\mathrm{K}_{2} \mathrm{CO}_{3}(0.1$ equiv) \\ $t$ - $\mathrm{BuOOH}$ (2.2 equiv) \\ $0.5 \mathrm{M} \mathrm{Na}_{2} \mathrm{~S}_{2} \mathrm{O}_{3}$ \\ $96 \%(2.4 \mathrm{~mol}$ scale $)$}

c

$\mathrm{MeOH}, \Delta$

$85 \%(0.2 \mathrm{~mol}$ scale $)$

Biginelli reaction

mp not reported

mp not reported

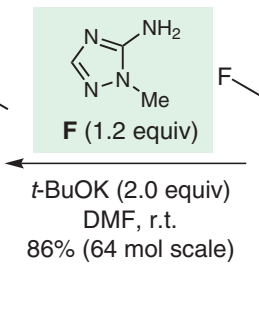

equiv)<smiles>COC(=O)c1c(-c2ccc(C)cc2)nc(Cl)nc1C(C)C</smiles>

mp not reported<smiles>CC(C)c1nc(N(C)c2ncnn2C)nc(-c2ccc(F)cc2)c1C=O</smiles>

Significance: BMS-644950 is a development candidate for the treatment of hypercholesterolemia. The route depicted delivered $>70 \mathrm{~kg}$ of the API in 35\% overall yield. The synthesis is noteworthy for the large-scale TEMPO oxidation $(\mathbf{H} \rightarrow \mathbf{I}, 83 \mathrm{~mol}$ scale) and Julia-Kocienski olefination $(\mathbf{A}+\mathbf{B} \rightarrow \mathbf{C}, 78 \mathrm{~mol}$ scale).
Comment: The Julia-Kocienski olefination was performed by adding LiHMDS to a mixture of the aldehyde $\mathbf{I}$ and the sulfone $\mathbf{J}$ in $\mathrm{THF}$ at $-70^{\circ} \mathrm{C}$ (Barbier conditions). In this way the E-alkene product was obtained with high stereoselectivity (E/Z up to 200:1). Note the use of dimethyl carbonate and DABCO for the $\mathrm{N}$-alkylation of $\mathbf{G}$. 